\title{
Addendum
}

\section{Addendum: Pesce et al. Irisin and Autophagy: First Update. Int. J. Mol. Sci. 2020, 21, 7587}

\author{
Mirko Pesce ${ }^{1, *}$, Patrizia Ballerini ${ }^{2, *}$, Teresa Paolucci ${ }^{3}$, Iris Puca ${ }^{4}$, Mohammad Hosein Farzaei ${ }^{5}$ and \\ Antonia Patruno ${ }^{1}$ (D)
}

Citation: Pesce, M.; Ballerini, P.; Paolucci, T.; Puca, I.; Farzaei, M.H.; Patruno, A. Addendum: Pesce et al. Irisin and Autophagy: First Update. Int. J. Mol. Sci. 2020, 21, 7587. Int. J. Mol. Sci. 2021, 22, 5117. https:// doi.org/10.3390/ijms22105117

Received: 30 April 2021

Accepted: 10 May 2021

Published: 12 May 2021

Publisher's Note: MDPI stays neutra with regard to jurisdictional claims in published maps and institutional affiliations.

Copyright: (c) 2021 by the authors. Licensee MDPI, Basel, Switzerland. This article is an open access article distributed under the terms and conditions of the Creative Commons Attribution (CC BY) license (https:// creativecommons.org/licenses/by/ $4.0 /)$
1 Department of Medicine and Aging Sciences, University G. d'Annunzio, 66100 Chieti, Italy; antonia.patruno@unich.it

Department of Neurosciences, Imaging and Clinical Sciences, University G. d'Annunzio, 66100 Chieti, Italy

3 Department of Oral, Medical and Biotechnological Sciences, University G. d'Annunzio, 66100 Chieti, Italy; teresa.paolucci@uniroma1.it

4 Sport Academy SSD, 65010 Pescara, Italy; pucairis@gmail.com

5 Pharmaceutical Sciences Research Center, Health Institute, Kermanshah University of Medical Sciences, Kermanshah 67146, Iran; mh.farzaei@gmail.com

* Correspondence: mirko.pesce@unich.it (M.P.); patrizia.ballerini@unich.it (P.B.)

We did not receive the copyright for Figure 2 in our published paper [1]. Now, we have received it from the correspondence author Ewa Pocheć [2]. Therefore, we would like to announce this addendum.

This addendum does not cause any changes to the results and conclusions in the original published paper.

\section{References}

1. Pesce, M.; Ballerini, P.; Paolucci, T.; Puca, I.; Farzaei, M.H.; Patruno, A. Irisin and Autophagy: First Update. Int. J. Mol. Sci. 2020, 21, 7587. [CrossRef] [PubMed]

2. Korta, P.; Pocheć, E.; Mazur-Biały, A. Irisin as a Multifunctional Protein: Implications for Health and Certain Diseases. Medicina 2019, 55, 485. [CrossRef] [PubMed] 